\title{
Forecasting Achievement Sports through Cooperative Learning in Handball Training in Physical Education
}

\author{
${ }^{1}$ Mohammed Majid Mohammed Salih ${ }^{(D *}$, ${ }^{1}$ Riyadh Saihood Hashim ${ }^{(D)},{ }^{2}$ Munadhil \\ Adil Kasim \\ ${ }^{1}$ College of Physical Education and Sport Sciences, University of Misan, Maysan, Iraq. ${ }^{2}$ Directorate of \\ Misan Education, Ministry of Education, Iraq.
}

Submitted 20 November 2020; Accepted in final form 23 January 2021.

\begin{abstract}
Background. This work studied 60 university students who were registered in two handball training classes in the second year of Physical Education and Sports Science throughout the academic year 2017 to 2018. Objectives. It aims to identify the impact of two different training styles (cooperative and traditional) on players' achievements and basic techniques in a handball learning unit. Methods. Hence, the sample was divided into the control and experiment groups. The experiment group was subjected to the cooperative training technique, whereas the control group was subjected to the traditional training (teacher-cantered) technique. The complying instruments were used to collect learning design inventory, handball achievement tests, handball techniques, and assessment forms. Results. The handball attitude scale revealed that cooperative training during a handball training class has a stronger link to students' sporting activities achievements, class attitude, and exercise skills compared to traditional training. Results of players' test range suggest that they prefer cooperative training. Conclusions. This study can help researchers and practitioners conduct Cooperative Learning intervention programs Physical Education in Schools and Universities.
\end{abstract}

\section{KEYWORDS: Balance, Flexible Flat Foot, Ground Reaction Force, Foot Pressure.}

\section{INTRODUCTION}

Sports achievement forecasting is essential for team supervisors, sports coaches, sponsors, the media and people betting on the teams (1). The extensive need for expert guidance regarding the outcomes of sporting activities is satisfied by a range of professional forecasts in the sports field (2). In addition, forecasting's provide forecasterstyle and professional source of guidance concerning sporting activities' achievement findings. Repaired forecasting's show the (professional) odds of sports makers (1), whereas forecasting's in sports achievements suggest the combined assumptions of all experts which propose accumulated expert forecasts regarding the teams
(3). Forecasting is used in sports to forecast achievement findings (4), which recommend an additional technique of achievement forecasting. Forecasting relies on the awareness of the selected training techniques. When a finding connected with a particular style circumstance occurs in training. In sports competitions, each factor contributes knowledge to the achievement; hence, the players' training method is an important winning factor in sports competitions $(5,6)$.

The accessibility of several forecasting styles increases questions regarding their efficiency in forecasting sporting activities, but the understanding of their comparative efficiency

*. Corresponding Author:

Mohammed Majid Mohammed Salih, Prof

E-mail: dr.mohmmed@uomisan.edu.iq 
remains limited because no research has studied forecasting technique training in sports $(1,7,8)$. Moreover, little is known about the possible importance of forecasts throughout training techniques and their performance or capability to enhance forecast precision if utilized scientifically. However, such knowledge and understanding are important because they might allow coaches to systematically earn the match on those achievements. They help sports decisionmakers enhance their projections. However, the current work empirically compares the forecast precision of training styles and uses science as the basis of those projections. It utilizes 60 university students who were registered in two handball classes in the second year of Physical Education and Sports Science during the academic year 2017 to 2018. In consideration of the importance of the championship to the coaches, we also identify if the projections of the training styles or their combinations allow sports achievement. Thus, we contribute to the sports forecasting literature by providing the first large-scale empirical study on the forecasting method that compares forecasting accuracy and ability in sports achievement.

The current study aims to test following null hypotheses at 0.05 It-level:

Ho1: No statistically significant difference exists in the sports achievement pretest mean scores between students in cooperative training and those in traditional training.

Ho2: No statistically significant difference exists in the sports achievement post-test mean scores between students in cooperative training and those in traditional training.

Abilities of /Ratings of/" or /strengths". In the competitive sporting activities, teams or players as well as advocates are interested in the ratings of the rival team as a measure of their capabilities or strengths and weaknesses. Common strategies are used for obtaining appropriate forecasting via flexible adaptive schemes which upgrade evaluations on the basis of historic efficiencies upon the availability of data about current efficiencies. Some forecasting schemes are based on an easy factor system, whereas others utilize statistical styles. Ability forecasting is often used for forecasting efficiencies in future sports competitions (9). In some sporting activities, forecasting is also utilized for deriving seeding which in turn can be used for forecasting as in (10). Unlike the forecasting discussed above, these schemes are not obtained directly from past performances but arise from "expert" understanding in training styles. Hence, this generally encompasses knowledge and understanding regarding past findings, but it might also consider forecasting's about future findings due to the growing popularity of handball amongst the youth. Coach forecasting's are a kind of data that are plentiful and readily available, and they have been effectively used in forecasting sporting activities (11). Another essential difference between forecasting and the capability scores discussed over is that they are an evaluation of finding probabilities in winning likelihoods in the case of sports competitions rather than of underlying capabilities. Nevertheless, the forecasting of sporting activities refer to the perceptions for optimal training which has two important implications. Complementary probabilities must be utilized as bookmakers' forecasting represent expectations for probabilities. In the claim of gaining prediction for a competition, the suggested gaining forecasting can be easily obtained from the forecasting for all competitors in sports competitions.

Cooperative learning strategy involves collectively utilizing skills that benefit each team learner to accomplish shared aims (12). It encourages learners to discuss and to teach one another; achievement develops when the learner learns information with the specific intent of teaching others in the team (13-15) discovered that learners in cooperative learning strategy teams utilize elaboration and metacognitive strategies frequently, thereby achieving a higher level of training than learners training individually and competitively. Huang (16) suggested that learners learning cooperatively in a team environment motivate one another to seek elaborative feedback to their responses and practice tasks, whilst some teachers are reluctant to use it as the motor aspect of physical education is missed and the academic goals of the subject must be matched with physical abilities (17).

Handball is a complex sport in which individual performance, including training, technical, physiological and psychological aspects, is very important for achievement (18, 
19). Handball is played in two periods of $30 \mathrm{~min}$ each, where two teams of seven players (goalkeeper and six field players) try to achieve the maximum number of goals. Despite its popularity, handball research has been scarce. However, the sport has been covered frequently in studies since 2010 (20). The most frequently studied topics include performance and success variables, physiological variable measurements and injuries physical capacities and conditions. However, universities still lack research training styles on handball $(21,22)$.

Universities have historically concentrated traditionally focused on instrumental content creation through individual and competitive tasks (23). Physical education focuses on athletics, testing and results, putting other content aside and not challenging the type of learning that students generated (24). Faced with this problem, more accessible and participatory models, which consider for any motor and/or psychological development in students, had slowly become more common including Co-operative learning (25). During the 1970s, the concept of cooperative work started to grow as a means of fostering social and academic skills in the classroom. Cecchini Estrada pointed out five fundamental elements in this pedagogical model (26): positive interdependence, promotive interaction, group processing, individual responsibility, and interpersonal skills (27). Researchers conclude that Cooperative Learning's true strength is its hybridization with other models (28). It results in reproducing approaches based on the individual success of a student without taking account of creating positive experiences for all by means of motor skills, which can positively influence student perception of the subject (29). In the last 20 years, several studies and metaanalysis of cooperative learning have been performed but they concentrated on curriculum issues such as math or education in general (3032). A large number of educational experiences have reflected the great spread of cooperative learning, but academics and educators need a study to determine its effectiveness in physical education, updating and extending previous analyzes in order to support teachers and researchers.

\section{MATERIALS AND METHODS}

Type of Research. This type of research includes quantitative research. It highlights that all collected data would go through some calculations before answering the research question in the study (33). In the current study, we have the training together style utilized in executing the cooperative learning strategy style and the traditional training technique for identifying the activity of handball classes. The training is commonly utilized within the goal of the experimental study style "control-experiment group pretest-posttest".

Table 1. Equivalent pre/post-test control group design

\begin{tabular}{lcccc}
\hline Groups & N & $\begin{array}{c}\text { Pre- } \\
\text { Test }\end{array}$ & X & $\begin{array}{c}\text { Post- } \\
\text { Test }\end{array}$ \\
\hline $\begin{array}{l}\text { Experimental } \\
\text { Group }\end{array}$ & 30 & $\mathrm{O} 1$ & $\mathrm{X}$ & $\mathrm{O} 2$ \\
$\begin{array}{l}\text { Experimental } \\
\text { Group }\end{array}$ & 30 & $\mathrm{O} 1$ & $\mathrm{X}$ & $\mathrm{O} 2$ \\
\hline
\end{tabular}

Participants. The participants of the current study comprised 60 university students who were registered in the two training classes of the handball course in the second year of college Physical Education and Sports Science teaching during the academic year 2017 to 2018. One of the classes was specified as the experimental group $(n=30)$, in which the cooperative training style was used. The second class was specified as the control group $(n=30)$, in which the traditional training style was used. Treatment groups were chosen randomly.

Table 2. The distribution of the sample

\begin{tabular}{lccc}
\hline Group & Control & Experimental & Total \\
\hline No. of the sample & 40 & 40 & 80 \\
\hline
\end{tabular}

Operational Definition. This work was prepared on the basis of a student-used method observed in several training classes in which I had been assigned in universities in Iraq. A pretest/posttest was designed on the basis of the course training respecting the course learning objectives and cooperative activities. The goal was to measure the pre-existing achievement of the players possessed before the execution of cooperative activities subject to this work and to compare such achievement to what the players knew as a result of the course experience after the application of cooperative training in unit learning. This test was designed to engage players 
with tasks that had to be trained in teams or groups, thereby requiring team train skills, collaboration, contributions and respecting others' point of views. The pretest and the posttest were applied at the beginning and at the end of the work to compare the players' progress. The results before and after the usage of cooperative learning training in learning units were collected.

Task. The sport was a collective handballtype game with adapted rules (30 players in each group during the training session, with the goal of defining the effect of two separate training styles (cooperative and traditional) on the accomplishments of players and basic handball learning techniques) in the classroom. The role to be done. The sample was therefore split into control and experimental groups. The group experimental a cooperative training technique, while the control group underwent a conventional (teacher-centered) training technique of the same group (per test and post-test).

Data Analysis. In this work, cooperative training was performed by players in a physical education team to handball game three units for nine weeks. Before the first session, a pretest was taken by the players. In each session, the players worked in groups solving a cooperative learning task that lasted 45-90 minutes. In this process, players took formal evaluations provided by the college as part of the syllabus. At the end of the study, a posttest was taken by players to compare the findings obtained in the pretest at the beginning of the work. After the collection of data utilizing the instruments already explained, such information was tabulated to be analyzed through graphs.

Table 3. The t-test findings for pre-test handball pre-experiment attitude

\begin{tabular}{lcccccc}
\hline & N & M & SD & df & T & Sig. \\
\hline Traditional Group & 30 & 19.98 & 1.89 & 58 & 0.438 & 0.674 \\
Cooperative Learning Group & 30 & 19.77 & 2.13 & 58 & & \\
Total & 60 & 19.75 & 2.01 & & & \\
\hline
\end{tabular}

The findings revealed no significant difference between the two groups on the pre-test $(\mathrm{t}(58)=0.438, \mathrm{p}>0.05)$.

\section{RESULTS}

Data from the pilot research studies were utilized to identify dependability estimates for the posttest. Cronbach alpha was utilized to determine the dependability of the posttest which was discovered to have a value of 0.80 . The mean of the posttest was 19.75 , with a conventional discrepancy of 2.01. The first reliant variable of the study was student achievement sports. This variable was operationally specified as a learner's rating on the posttest one-way ANOVA, and Scheffe's several comparison test was utilized to analyses the data in the current study. The two training elements comprised the traditional training and cooperative training groups.

The findings of Table 4 show the skills of the two post-test classes. The test results for the experimental group have been substantially higher than those for the control group $(\mathrm{t}(58)=7.891, \mathrm{p}<$ $0,05)$. These results indicate that the cooperative training approach has a positive effect on student success. On the contrary, the teacher-centered class students did not achieve success in handball skills. The sophistication of handball skills can be easily concluded for people working in groups, and students face difficulty in game sports exercise the basic skills by teacher- method.

Table 4. The t-test results for post-test scores of the groups

\begin{tabular}{lccccc}
\hline & M & SD & df & T & Sig \\
\hline Traditional Group & 33.59 & 2.40 & 58 & $7.891 *$ & 0.001 \\
Cooperative Learning Group & 48.73 & 2.36 & & & \\
\hline
\end{tabular}

Achievements throughout the groups were compared utilizing $(2 \times 2)$ factorial styles. Inter student elements consisted of a group with two levels of cooperative and traditional learning. The dependent variable was sports achievement towards handball training in physical education.
The analyses of all reliant steps were carried out via Statistical Package for the Social Sciences 23. The alpha degree selected for statistical significance was 0.05 . The descriptive analyses were performed on the data collected in the current study. With regard to the first research 
question, cooperative learning training was utilized in the experimental group after looking for strategies to further integrate handball training in physical education. The findings obtained in the pretest and posttest show that collaborative training during the performance of cooperative learning strategy tasks was developed throughout the course in the experimental group. In fact, we can affirm that certain "novel" activities raise players' interest. Subsequently, their motivation towards training also arises.

\section{DISCUSSION}

The aim of this study was to assess the effect on players' achievements and basic technologies of handball learning of two different training styles (Cooperative and traditional). The experimental group, according to the hypothesis, had superior influence over certain accomplishments and basic techniques in handball learning at both the individual and collective levels on was superior to the control group. These differences were relevant during the pre-test and post-test, i.e., the intergroup training. Every team in the experimental group had better results and basic strategies (pre-test and post-tests for groups) and better skills (after-testing). In addition, the findings of this study are in agreement with previous studies (34). As a finding of the current study which was performed to identify the of the cooperative training strategy and the traditional training strategy on both practical and theoretical skill obtainment in the handball training class, we can state that the theoretical and practical skills of learners who were subjected to the cooperative training development greater than those of the learners who were subjected to the traditional training. These findings have similarities with previous research results (35-38). The cooperative training strategy team was more effective than the control team because the cooperative training strategy team learners assisted one another to train best, inspired one another throughout activity performance, and functioned as a team outside of the training class meetings to show optimal performance during the activity. These results confirm previous studies in collective game sports (39-41), and in for cooperative learning. They reinforce (42) assumptions regarding the value of cooperative learning in the regulation of motor behaviors and mutual tactical skills development. Confirm study (39) despite methodological variations, findings show that cooperative conditions have strong motor skills impact. With respect to the theoretical cooperation context, it appears that co-operating training uses the purpose and the tactics of the game to develop the rate of motor and tactical skills. Cañabate suggested that the interpersonal relationships developed by the system for cooperative learning between the students led to the increase in their physical, academic, social and affective skills (43). The findings are in line with Gillies conclusions about training in cooperative situations (44). Therefore, our experiment confirms Hojo findings on the role of co-op training in team sports development (45). Such findings reveal that cooperative training style is certainly more advance-dangerous than the traditional training style. Therefore, players will have positive class training for a handball training class. This study was the very first time that these players were subjected to the cooperative training style which enabled them to raise self-confidence, improve students' connections, and enjoy the training procedure as they also struggle for their colleagues' learning and increase pleasure whilst playing sporting activities. All of these advantages favorably impact learners' mindset towards the unit learned. Therefore, players assisted one another spontaneously. These truths must also be considered factors for why the cooperative training style is better than the traditional training style. The result of the current study has resemblances with previous studies which were performed to show the positive impact of the cooperative learning strategy on learners' techniques and physical skills (42, 46, 47 48).

\section{CONCLUSIONS}

According to the outcome, the cooperative training is the most suitable style because it increases the attractiveness and enjoy ability of sports training. Moreover, cooperative training style should be applied in physical education and sports science lessons. This technique can be disseminated through the evidence of academic knowledge, lesson approach, achievement of learners and performance skills. Future studies should study the long-term impact on student skills of each model. 


\section{APPLICABLE REMARKS}

- Cooperative training provides our students with many meaningful learning opportunities, and the use of both models offers many advantages.

- We strongly believe that these models provide many advantages that a conventional method of training cannot offer.

- The repercussive is that student motivation can be enhanced and student conduct can be strengthened by the proper use of these models!
- Teachers must be prepared to make deliberate improvements to enhance the teaching and experience of their students. Teachers must also be encouraged and compensated for using these models.

- It is important to adapt and adjust our pedagogical approach where appropriate, and by adopting the cooperative training model in sports games, we can give our students many advantages that can have a positive effect on basic game skills.

\section{REFERENCES}

1. Wunderlich F, Memmert D. The Betting Odds Rating System: Using soccer forecasts to forecast soccer. PLoS One. 2018;13(6):e0198668. doi: 10.1371/journal.pone.0198668 pmid: 29870554

2. Stein M, Janetzko H, Seebacher D, Jäger A, Nagel M, Hölsch J, et al. How to Make Sense of Team Sport Data: From Acquisition to Data Modeling and Research Aspects. Data. 2017;2(1). doi: 10.3390/data2010002

3. Spann M, Skiera B. Sports forecasting: a comparison of the forecast accuracy of prediction markets, betting odds and tipsters. J Forecast. 2009;28(1):55-72. doi: 10.1002/for.1091

4. Razali N, Mustapha A, Utama S, Din R. A Review on Football Match Outcome Prediction using Bayesian Networks. J Physic Conf Series. 2018;1020(2). doi: 10.1088/1742-6596/1020/1/012004

5. Serrano J, Shahidian S, Sampaio J, Leite N. The importance of sports performance factors and training contents from the perspective of futsal coaches. J Hum Kinet. 2013;38:151-160. doi: 10.2478/hukin2013-0055 pmid: 24235991

6. Ortega-Becerra M, Sigüenza-Iglesias JA, Asián-Clemente JA. Effects of 4-week training with balls of different weights on throwing velocity in handball players. J Physic Edu Sport. 2019;19(1):344-349.

7. Graham SR, Cormack S, Parfitt G, Eston R. Relationships Between Model Estimates and Actual MatchPerformance Indices in Professional Australian Footballers During an In-Season Macrocycle. Int J Sports Physiol Perform. 2018;13(3):339-346. doi: 10.1123/ijspp.2017-0026 pmid: 28714739

8. Felsen P, Agrawal P, Malik J. What will Happen Next? Forecasting Player Moves in Sports Videos. 2017 IEEE International Conference on Computer Vision (ICCV)2017. p. 3362-3371.

9. Soyiri IN, Reidpath DD. Evolving forecasting classifications and applications in health forecasting. Int J Gen Med. 2012;5:381-389. doi: 10.2147/IJGM.S31079 pmid: 22615533

10. Stekler HO, Sendor D, Verlander R. Issues in sports forecasting. Int J Forecast. 2010;26(3):606-621. doi: 10.1016/j.ijforecast.2010.01.003

11. Yang YS. Predicting Regular Season Results of NBA Teams Based on Regression Analysis of Common Basketball Statistics: University of California at Berkeley; 2015.

12. Garfield J. Teaching Statistics Using Small-Group Cooperative Learning. J Stat Edu. 2017;1(1):12-28. doi: 10.1080/10691898.1993.11910455

13. Hammar Chiriac E. Group work as an incentive for learning - students' experiences of group work. Front Psychol. 2014;5:558. doi: 10.3389/fpsyg.2014.00558 pmid: 24926282

14.Hammouri W, Ay K, Al-Dababseh M. Impact of mastery cooperative learning strategy and individual inquiry on attaining the technical aspects of the stages of shot put and digital achievement using the linear method among the students of the University of Jordan. J Physic Edu Sport. 2016;16(1):50.

15. Simsek A, Balaban J. Learning Strategies of Successful and Unsuccessful University Students. Contemporary Edu Tech. 2010;1(1):294-310. doi: 10.30935/cedtech/5960

16. Huang C-Y. The effects of cooperative learning and model demonstration strategies on motor skill performance during video instruction. Proceed Nat Sci Council. 2000;2:255-268. 
17. Casey A, MacPhail A. Adopting a models-based approach to teaching physical education. Physic Edu Sport Pedagogy. 2018;23(3):294-310. doi: 10.1080/17408989.2018.1429588

18. Antonis M, Dimitris H, Zacharoula P, Vasilis S, Ioannis VS. Analyses of technical and tactical data in attack and defense at high level handball teams. Journal of Physical Education and Sport. 2019;19(1):193-200.

19. Evhen P, Valeria T. Peculiar properties and dynamics of physiological indicators in Handball team. $J$ Physic Edu Sport. 2017;17(1):335.

20. Nouatin BK, Gouthon P, Messan F, Dansou PH, Amoussou-Guénou D, Nigan IB, et al. Context of handball practice and level of integration of fitness capacities to training schedules among players in southern Benin. J Physic Edu Sport. 2014;14(3):371.

21.Broch TB. Norwegian handball and gender: Towards a cultural sociology of sport: Norwegian School of Sport Sciences; 2014.

22. Madalina-Gabriela P, Ion M. Study on the improvement of coordinating capabilities at the level of handball teams (junior III), with the optimization of the technical-tactical potential. J Physic Edu Sport. 2018;18:2106.

23. Wihlborg M, Robson S. Internationalisation of higher education: drivers, rationales, priorities, values and impacts. Europ J Higher Edu. 2017;8(1):8-18. doi: 10.1080/21568235.2017.1376696

24.Fyall G, Metzler MW. Aligning Critical Physical Education Teacher Education and Models-Based Practice. Physic Edu. 2019;76(1):24-56. doi: 10.18666/tpe-2019-v76-i1-8370

25.Jung H, Choi E. The importance of indirect teaching behaviour and its educational effects in physical education. Physic Edu Sport Pedagogy. 2014;21(2):121-136. doi: 10.1080/17408989.2014.923990

26. Cecchini Estrada JA, Gonzalez Gonzalez-Mesa C, Llamedo R, Sanchez Martinez B, Rodriguez Perez C. The impact of cooperative learning on peer relationships, intrinsic motivation and future intentions to do sport. Psicothema. 2019;31(2):163-169. doi: 10.7334/psicothema2018.305 pmid: 31013241

27. Walker E, Johnson IL. Using Best Practices when Implementing the Cooperative-Learning Theory in Secondary Physical Education Programs. Strategies. 2018;31(4):5-11. doi: 10.1080/08924562.2018.1465870

28. Ruiz-Montero PJ, Chiva-Bartoll O, Salvador-García C, González-García C. Learning with Older Adults through Intergenerational Service Learning in Physical Education Teacher Education. Sustainability. 2020;12(3). doi: 10.3390/su12031127

29. Invernizzi P, Crotti M, Bosio A, Cavaggioni L, Alberti G, Scurati R. Multi-Teaching Styles Approach and Active Reflection: Effectiveness in Improving Fitness Level, Motor Competence, Enjoyment, Amount of Physical Activity, and Effects on the Perception of Physical Education Lessons in Primary School Children. Sustainability. 2019;11(2):405-420. doi: 10.3390/su11020405

30. Bores-Garcia D, Hortiguela-Alcala D, Fernandez-Rio FJ, Gonzalez-Calvo G, Barba-Martin R. Research on Cooperative Learning in Physical Education. Systematic Review of the Last Five Years. Res Q Exerc Sport. 2020:1-10. doi: 10.1080/02701367.2020.1719276 pmid: 32023176

31.Erdogan F. Effect of Cooperative Learning Supported by Reflective Thinking Activities on Students' Critical Thinking Skills. Eurasian J Edu Res. 2019;19(80):1-24. doi: 10.14689/ejer.2019.80.5

32. Gambari AI, Yusuf MO. Relative effectiveness of computer-supported Jigsaw II, STAD and TAI cooperative learning strategies on performance, attitude, and retention of secondary school students in physics. J Peer Learn. 2017;10(1):76-94.

33. Kasim MA, Abed AZ, Sameer SA, Othman AT. Predicting Effect Implementing the Jigsaw Strategy on the Academic Achievement of Students in Mathematics Classes. Intl Electronic J Math Edu. 2019;15(1). doi: $10.29333 /$ iejme/5940

34. Tarp J, Domazet SL, Froberg K, Hillman CH, Andersen LB, Bugge A. Effectiveness of a School-Based Physical Activity Intervention on Cognitive Performance in Danish Adolescents: LCoMotion-Learning, Cognition and Motion - A Cluster Randomized Controlled Trial. PLoS One. 2016;11(6):e0158087. doi: 10.1371/journal.pone.0158087 pmid: 27341346

35. Barrett T. Effects of Cooperative Learning on Performance of Sixth-Grade Physical Education Students. J Teachn Physic Edu. 2005;24(1):88-102. doi: 10.1123/jtpe.24.1.88 
36. Castillo AV, Bartoll OC, Peris CC. Aprendizaje comprensivo-cooperativo en la enseñanza del balonmano: Efectos sobre el clima motivacional. e-balonmano com: Revista de Ciencias del Deporte. 2017;13(1):53-66.

37.Lafont L. Cooperative learning and tutoring in sports and physical activities. Cooperative learning in physical education: A research based approach: Routledge; 2012. p. 136-149.

38. Oliveira LS, De Oliveira WRF, De Carvalho Filho JJ, Borges CJ, De Oliveira GL, De Oliveira TAP, et al. Cooperative games as a pedagogical strategy for decreasing bullying in physical education: notable changes in behavior. J Physic Edu Sport. 2017;17(3):1054-1060.

39. Huang M-Y, Tu H-Y, Wang W-Y, Chen J-F, Yu Y-T, Chou C-C. Effects of cooperative learning and concept mapping intervention on critical thinking and basketball skills in elementary school. Think Skills Creativity. 2017;23:207-216. doi: 10.1016/j.tsc.2017.01.002

40.Legrain P, Escalié G, Lafont L, Chaliès S. Cooperative learning: a relevant instructional model for physical education pre-service teacher training? Physic Edu Sport Pedagogy. 2018;24(1):73-86. doi: 10.1080/17408989.2018.1561838

41. Shang Y, editor Analysis of Athletes' Physiological Arousal Stimulation Strategies in Sports Competition Based on Cooperative Learning Theory. International Workshop on Advances in Social Sciences; 2019; China.

42. Wallhead T, Dyson B. A didactic analysis of content development during Cooperative Learning in primary physical education. Europ Physic Edu Rev. 2016;23(3):311-326. doi: $10.1177 / 1356336 \times 16630221$

43. Cañabate D, Garcia-Romeu ML, Menció A, Nogué L, Planas M, Solé-Pla J. Cross-Disciplinary Analysis of Cooperative Learning Dimensions Based on Higher Education Students' Perceptions. Sustainability. 2020;12(19). doi: 10.3390/su12198156

44.Gillies R. Cooperative Learning: Review of Research and Practice. Australian J Teach Edu. 2016;41(3):39-54. doi: 10.14221/ajte.2016v41n3.3

45.Hojo M, Fujii K, Inaba Y, Motoyasu Y, Kawahara Y. Automatically recognizing strategic cooperative behaviors in various situations of a team sport. PLoS One. 2018;13(12):e0209247. doi: 10.1371/journal.pone.0209247 pmid: 30562367

46. Bodsworth H, Goodyear VA. Barriers and facilitators to using digital technologies in the Cooperative Learning model in physical education. Physic Edu Sport Pedagogy. 2017;22(6):563-579. doi: 10.1080/17408989.2017.1294672

47.Dyson B, Strachan K. The ecology of cooperative learning in a high school physical education Pprogramme. Waikato J Edu. 2016;10(1). doi: 10.15663/wje.v10i1.335

48. McMaster KL, Lembke ES, Shin J, Poch AL, Smith RA, Jung P-G, et al. Supporting teachers' use of data-based instruction to improve students' early writing skills. J Edu Psychol. 2020;112(1):1. 